\title{
ÉTHOS CRÍTICO E GOVERNAMENTALIDADE EM MICHEL FOUCAULT
}

\author{
Rogério Luís da Rocha Seixas ${ }^{1}$
}

\section{RESUMO:}

Será possível assinalar qual seja a principal questão para o exercício filosófico hoje? A este respeito, a resposta de Michel Foucault é direta: o diagnóstico crítico de nossa atualidade. Partindo desta posição do autor, o objetivo de nosso texto é discutir o sentido de Filosofia caracterizando-se como um exercício crítico e sua principal função: identificar o acontecimento relevante na atualidade, designando assim a atividade de diagnóstico como específica da filosofia. Partindo desta postura, a visão sobre o sentido de Filosofia deixa de ser uma mera adesão aos sistemas ou aos dogmas, caracterizando-se como um exercício crítico, com o objetivo de se buscar pensar diferentemente do que se pensa e o mais crucial ainda: identificar o acontecimento relevante na atualidade, passível de ser tratado filosoficamente. Nossa hipótese a ser trabalhada, parte da observação referente a um ativismo filosófico, ético e político, descrito como atitude ou, mais ainda, como um éthos na reflexão foucaultiana, que engloba todo o seu trabalho, mas que se torna mais pungente em sua, assim denominada, última fase ou fase ética, envolvendo a temática da governamentalidade. Partindo desta temática, discutiremos o vínculo entre ética e política, exatamente por se tratar da ligação entre liberdade, verdade, poder e resistência; destacando-se a relação entre a prática do governo dos outros e o exercício do governo de si. Possibilita analisar a articulação entre verdade, ação política e governamento, quando se trata de identificar a existência de uma atitude política que ganha o contorno de uma atitude ética em se recusar a ser governado de tal forma. Nesse momento, o autor se volta para o éthos crítico enquanto prática de liberdade como forma de recusa ao exercício de governamento excessivo na conduta dos indivíduos.

Palavras-Chave: Contra conduta, Éthos Crítico, Governamento, Liberdade, Política.

\section{ÉTHOS CRITIC AND GOVERNMENTALITY IN MICHEL FOUCAULT}

\begin{abstract}
:
Is it possible to point out the main question for the philosophical exercise today? In this respect, Michel Foucault's answer is straightforward: the critical diagnosis of our actuality. Starting from this position of the author, the objective of our text is to discuss the meaning of Philosophy, characterizing itself as a critical exercise and its main function: to identify the relevant event in the present time, thus designating the diagnostic activity as specific to philosophy. Starting from this position, the vision about the meaning of Philosophy ceases to be a mere adhesion to systems or dogmas, characterizing itself as a critical exercise, with the objective of trying to think differently from what is thought and the most crucial still: to identify the relevant event today, which can be treated philosophically. Our hypothesis, to be worked on, is based on the observation of a philosophical, ethical and political activism, described as an attitude or, moreover, as an ethos in Foucauldian reflection, which encompasses all of his work, but which becomes more poignant in his, so-called, last phase or ethical phase, involving the theme of governmentality. Starting from this theme, we will discuss the link between ethics and politics, precisely because it is the link between freedom, truth, power and resistance; highlighting the relationship between the practice of the government of others and the exercise of self-government. It makes it possible to analyze the articulation between truth, political action and governance, when it comes to identifying the existence of a political attitude that gains the outline of an ethical attitude in refusing to be governed in such a way. At
\end{abstract}

\footnotetext{
${ }^{1}$ Pesquisador-docente convidado do grupo de pesquisa Bildung-IFPR. Doutor em Filosofia (UFRJ). Email: lucseixas@yahoo.com.brou rogeriosrjb@gmail.com.
} 
this point, the author turns to the critical ethos as a practice of freedom as a form of refusal to exercise excessive governance in the conduct of individuals.

Keywords: Against Conduct, Éthos Critic, Governance, Freedom, Politics.

\section{Introdução}

A Aufklärung é representada por um movimento de análise crítica caracterizada como "uma reflexão fillosófica que diz respeito apenas ao modo de relação reflexiva com o presente" (FOUCAULT, 2001, p. 1391). Introduz-se uma tensão entre o que nós somos e a atualidade que experimentamos a partir da expressão do éthos crítico, cujo objetivo é de problematizar a nossa condição na atualidade. Desta maneira, fez-se necessário redefinir o que é crítica e negar que esta signifique simplesmente a emissão de julgamentos. Temos um convite ao exercício prático, não simplesmente dos atos, intenções ou desejos, mas de escolher um modo de ser, incitando a transformação. A tarefa mais importante por realizar, partindo de um diagnóstico crítico da atualidade, não se limita a compreender quem somos nós no presente, quais são as subjetividades instituídas, mas consiste em:

Seguindo as linhas de vulnerabilidade da atualidade, em conseguir apreender por onde e como isso que existe hoje poderia não ser mais o que é na produção de subjetivações. Trata-se de buscar uma espécie de fratura virtual, que abre um espaço de liberdade, de transformação possível (FOUCAULT, 2001, p. 235).

A crítica produz efeitos propriamente éticos e políticos, necessitando-se determinar contra o que devemos lutar para nos libertarmos impreterivelmente de nós mesmos. Lutas contra as formas de exploração iniciadas no século XIX e lutas contra a submissão das subjetividades contemporaneamente. Estas lutas, atualmente, se apresentam de modo associado, trazendo uma novidade diferencial: o capitalismo contemporâneo associou de modo imanente, produção material e produção de subjetividade - o que se tornou centro de disputas políticas e econômicas. "É a própria essência do lucro capitalista que não se reduz ao campo da mais-valia econômica: ela está também na tomada de poder da subjetividade". Perante uma atualidade demarcada como espaço onde podem emergir novas conformações de relações de poder, novas

\begin{tabular}{|l|l|l|l|l|}
\hline Q Povista Dialectus & Ano 4 & n. 11 & Agosto - Dezembro 2017 & p. 69-87
\end{tabular}


subjetividades e formas de assujeitamento ${ }^{2}$. Sendo assim, pensar a partir deste caráter ontologicamente crítico da nossa existência, permite aventar a possibilidade de multiplicarmos os espaços de liberdade e autonomia em meio à mesmice já constituída de nossas rotinas de pensamento e ação no mundo, às quais nos tornarmos acomodados. Pretende-se um modo de relação com o presente onde os meios de transformação se constituirão como uma análise crítica que possibilite constituir formas de subjetividades em singularidades transformáveis. Michel Senellart, afirma que "é nesta linhagem que Foucault se situa. Esta atitude crítica consiste em repensar a Aufklärung, não como a aurora do reino luminoso da razão, mas como esforço permanente para interrogar as racionalidades, tagarelas ou mudas, que nos conduzem" (SENELLART, 1995, p.5). Segundo Escobar, para Foucault, há então uma tarefa que se expressa de fato como sendo uma "escolha ética e política que precisamos fazer a cada dia que é determinar qual é o perigo principal” (ESCOBAR, 1984, p.44). Na perspectiva foucaultiana, o diagnóstico da atualidade refere-se às relações complexas entre os indivíduos e o poder. Isso porque é preciso acompanhar, sobretudo, a mobilidade das relações de poder. Por tratar-se de um cenário em movimento, haverá sempre "perigos". Mas para diagnosticar o perigo, como alerta Paul Veyne, precisamos desviar-nos de um trabalho em que este perigo seja considerado como um "sentido", "essência" ou "força oculta", buscando encontrar uma entidade ou força demoníaca que a tudo e a todos domine. Por isso, pensaremos os perigos ao modo da "parte oculta" de um iceberg (VEYNE, 1982, p.158). O éthos crítico, enquanto atitude crítica sobre nós mesmos, aposta na capacidade de abrir o espaço possível de liberdade - não se completando definitivamente, mas deixando sempre uma abertura para a possibilidade de mudanças, para a experiência possível de um auto desprendimento e de nos inventarmos sempre. Uma busca e aposta em nos governarmos a nós mesmos, porém sabedores de que não há um governo de si sem uma relação direta com governo dos outros. Afirme-se que a liberdade para a atividade do éthos é sua condição, objeto e objetivo. Ao mesmo tempo, destaque-se que aqui não é apresentada como uma possibilidade ética entre outras, mas a possibilidade própria da ética. Em sua descrição, não possui uma origem em si, sendo construída através de um permanente questionamento histórico inserido nas práticas do sujeito consigo mesmo e com outros.

${ }^{2}$ Termo que significa a condição do indivíduo em estar "sujeitado a alguém ou a alguma coisa".

\begin{tabular}{|c|c|c|c|c|}
\hline Rovista Dialectus & Ano 4 & n. 11 & Agosto - Dezembro 2017 & p. $69-87$ \\
\hline
\end{tabular}


Contudo, devemos observar que, a definição de governo destacada anteriormente, não se resume ao como somos conduzidos - também se reflete na ação de como nos conduzimos ou como nos deixamos conduzir; pode-se dizer que denota a ideia de como nos deixamos governar. Como observa Oksala: "Governar não é determinar fisicamente a conduta de objetos passivos. Envolve oferecer razões pelas quais os governados deveriam obedecer, significando que podem questionar as razões do porque são governados" (OKSALA, 2011, p.108). Nesta condição, podemos observar que, através da noção de ato poder enquanto governamento ${ }^{3}$ (isto é, a partir da necessidade de se problematizar o como governar e a quem governar) surge em seu bojo uma questão referente à "como não ser governado ou como não ser governado de tal maneira por tais pessoas ou para tal e tal fim?" (FOUCAULT, 1990, p.37). Há um querer governar mais a si mesmo, resistindo a não ser governado em determinadas circunstâncias, de qualquer maneira, ou por qualquer um. Porém, precisa-se esclarecer que, de alguma forma, se é governado. Não se trata, portanto, de renúncia ou escape das relações de poder, pois o que se percebe é que o governar a si mesmo está diretamente ligado à ação de ser governado ou governar os outros. O caráter desta atitude não expressa o sentido de um desgoverno absoluto ou um anarquismo fundamental. O que existe é uma inquietação em ser conduzido de tal forma e com tal intensidade, que possa haver, assim, uma dominação quase total. Fica evidente como a noção de governo permite elaborar uma melhor compreensão de práticas de liberdade ou formas de resistência que implicam em como não se deixar conduzir de tal modo ou por determinado motivo. Há o que se pode identificar como uma prática ou uma forma de atitude assumida como o que identificamos como um éthos crítico, vinculado à questão de como não se deixar governar dessa maneira. O seu exercício questiona as razões para se governar de tal modo e consequentemente, se se deve ou não obedecer a quem ou o porquê se quer governar. Porém, qual o sentido de crítica aludido pelo autor? Afirma-se a necessidade de se avaliar uma crítica genealógica, partindo da redefinição do próprio sentido de crítica, recusando sua designação como forma de determinar julgamentos positivos ou negativos sobre as coisas ou resumindo-se a um mero denuncismo. Adverte o autor: "Uma crítica não consiste em dizer que as coisas não estão bem como estão. Consiste em ver em que tipos de noções conhecidas, de modos de pensar estabelecidas e

\footnotetext{
3 Termo utilizado e sugerido por Alfredo Veiga-Neto, inspirado do termo derivado do francês (gouvernement) para diferenciar o ato-poder enquanto condução de condutas da noção comum de governo, enquanto instituição administrativa, social e política.
}

\begin{tabular}{|l|l|l|l|l|}
\hline Q Rovista Dialectus & Ano 4 & n. 11 & Agosto - Dezembro 2017 & p. 69-87 \\
\hline
\end{tabular}


não examinados, as práticas aceitas se baseiam" (FOUCAULT, 1990, p.35). Traça-se uma relação direta entre essa crítica genealógica e a crítica kantiana ligada a Aufklärung. Os importantes fatores presentes nesta associação para a análise foucaultiana, podem ser caracterizados, partindo da sua interpretação própria do texto kantiano. Kant, ao se questionar sobre a Aufklärung, coloca de maneira inédita a sua própria atualidade a tratando como problema filosófico: através de um trabalho crítico sobre os limites, não só do conhecimento, como também da ação humana, objetivando reformular a questão do uso da razão de modo autônomo e crítico. Depois, pode-se observar que, ao fundo desta questão, outra mais essencial se formula: Qual é o campo atual das experiências possíveis? Associa-se a noção de experiência com a de limites. Todavia, o ponto final importante para a discussão ética e política em Foucault, a partir de uma reinterpretação da crítica kantiana e a sua relação com a Aufklärung, ilustra-se através da seguinte questão: “O que somos nós hoje?” Obviamente, refere-se, aqui, às formas de subjetividades assujeitadas por diferentes técnicas de governo, que constituem o que nós somos hoje ou como nos identificamos como o que nós somos. $\mathrm{O}$ problema não passa pela esfera de descobrir o que nós somos, mas deixarmos de ser o que somos. Associa-se assim, a partir da descrição destes pontos, como se associam os limites a nós impostos, a avaliação de novas formas de experiência e a iniciativa de transformarmos nossos modos de ser. Desta forma, quando analisa e desenvolve suas interpretações próprias referentes ao opúsculo de Kant quanto à questão: “Was ist Aufklärung?" Foucault destaca que se inaugura uma "ontologia crítica do presente, buscando as condições e as indefinidas possibilidades de nos transformamos a nós próprios. Exigindo sempre um trabalho sobre nossos limites, isto é, um labor paciente que dá forma à impaciência da liberdade" (FOUCAULT, 2001, p.1397). Inexiste o intuito de se restaurar ou definir uma identidade, a prática da "ontologia crítica do presente" opera esfacelando o sujeito-identidade, opondo-o contra si mesmo e interrogando as múltiplas facetas históricas de que é formado. Nesse sentido, há uma passagem em Deleuze que diz: "A história, segundo Foucault, nos cerca e nos delimita; não diz o que somos, mas aquilo de que estamos em vias de diferir; não estabelece nossa identidade, mas a dissipa em proveito do outro que somos" (DELEUZE, 1992, p. 24). Em suma, a ontologia do presente, como projeto histórico-filosófico, assume a tarefa de "dessubjetivar a questão filosófica pelo recurso ao conteúdo histórico, libertar os conteúdos históricos pela interrogação sobre os efeitos de poder cuja verdade - essa que eles pressupõem e marcam - os afeta” (FOUCAULT, 1990, p.31).

\begin{tabular}{|l|l|l|l|l|}
\hline Qevista 2 ialectus & Ano 4 & n. 11 & Agosto-Dezembro 2017 & p. 69-87
\end{tabular}


A crítica das relações que podem se estabelecer entre os jogos de verdade, as práticas de exercício de governamento de poder e liberdade, não se reduzem à mera caracterização de um modo de ser em determinado tempo ou época, mas sim à abertura de um espaço para práticas de liberdade. Deve-se levar em grande importância que não basta "diagnosticar o que se é, mas sim como se poderá deixar de ser o que se é" (FOUCAULT, 2001, p.1257). Precisa se abrir um espaço de práticas de transformação possível. No prefácio escrito no livro de Canguilhem, O normal e o patológico, Foucault destaca que a "Aufklärung é um questionamento da razão como despotismo e como luz; ela está presente em nossa atualidade como indagação constante do Ocidente sobre as suas possibilidades hoje e sobre as liberdades que the são possíveis" (FOUCAULT, 2001, p.1587). A interação entre os domínios do poder, da verdade e ética, determinam a condição de possibilidade e limites da subjetividade. Sob este aspecto, de uma atitude crítica sobre o que nós somos, enquanto sujeitos históricos, e a condição de menoridade, aproximando crítica e Aufklärung, foca-se essencialmente "o feixe de relações que ligam um ao outro, ou um a dois outros, o poder, a verdade e o sujeito, constituindo o núcleo da temática da governamentalidade" (FOUCAULT, 1990, p.39).

\section{A Questão do Governo e a Aufklärung}

Quando nos referimos ao significado do termo governo, qual é de fato sua conotação? Este termo apresenta principalmente o sentido de exercício do poder como ação de condução de condutas, fazendo alusão "à maneira pela qual conduzimos a nós mesmos, como nos deixamos conduzir e como somos conduzidos, enfim, como nos comportamos sob o efeito de uma conduta, que seria ato de conduta ou de condução" (FOUCAULT, 2009, p.69). Desta forma, a questão da governamentalidade é apresentada como uma problematização presente em nossa racionalidade política atual. Existe uma preocupação quanto à liberdade do uso da razão e como os indivíduos podem encontrar obstruções para seu uso - e, neste caso, colocam-se sob a tutela de outros. Não parece apressado dizer: "Colocam-se sob o governo de outros excessivamente". Foucault afirma que se pode descrever a Aufklärung como uma "modificação da relação pré-existente ligando, poder, autoridade e o uso da razão" (FOUCAULT, 2001, p.388). Na conferência Qu`est-ce que la critique? Proferida por 
Foucault em 1978, formula-se a caracterização do que passa a denominar como atitude crítica, descrevendo-a, nesta oportunidade, como uma "virtude"; como uma atitude crítica, situada no interior da questão da arte de governar os homens, ou, mais especificamente, enquanto descrita como uma virtude que se opõe aos múltiplos modos de assujeitamento, promovidos pelas artes de governar como modalidade de um poder pastoral secular (Foucault, 1990, p.38). Então, definitivamente, esta caracterização da atitude crítica como virtude, segundo Kraemer "permite inscrevê-la na problematização da governamentalidade" (KRAEMER, 2011, p.290). Em qual circunstância? Como uma contra conduta que se refere a uma noção "positiva do termo conduta - contra conduta 4 no sentido de lutas contra procedimentos postos em ação para condução dos outros" (FOUCAULT, 2009, p. 258-259). Essa referência mais direta a este tipo de governamentalidade se justifica pela técnica de fixação de identidades para os indivíduos, exatamente por causa da relação de obediência entre o diretor de consciência e o conduzido (prática comum do pastorado cristão institucionalizado) produzindo-se sempre, por parte do conduzido, uma verdade sobre si mesmo - verdade que se coliga com a obediência; verdade entendida como:

Dogma; verdade que implica também na medida em que esse direcionamento implica em certo modo de conhecimento particular e individualizante; e, enfim, na medida em que esse direcionamento se desdobra como uma técnica reflexiva comportando regras gerais, conhecimentos particulares, preceitos, métodos de exame, confissões e entrevistas (FOUCAULT, 1990, p.36).

Sabemos que, a partir de uma explosão das artes de governar no século XV, que se apresentam as técnicas do pastorado, adequadas agora a outras modalidades de governamento dos homens, como: “A arte pedagógica, arte política e arte econômica - e todas as instituições de governo, no sentido amplo que tinha a palavra nessa época" (FOUCAULT, 2001, p. 37). Gros ainda observa que "as artes de governar os outros, de modo geral, produzem a obediência do sujeito a um modo de discurso de verdade" (GROS, 2006, p. 161). Obediência às verdades externas que impõem de alguma maneira, seu assujeitamento. Nesse contexto, exercer a crítica expressa uma decisão de apenas aceitar como verdade aquilo a respeito do que se pode encontrar em si mesmo uma relação crítica com as verdades externas e com a sua verdade. Não se aceita ser

\footnotetext{
${ }^{4}$ Este termo (contra conduta) busca diferenciar a atitude crítica de alguma vinculação com ideia de revolta, denotando a concepção de buscar recusar um tipo de governamento para se conduzir de outro modo.
}

\begin{tabular}{|l|l|l|l|l|}
\hline Revista Dialectus & Ano 4 & n. 11 & Agosto-Dezembro 2017 & p. 69-87 \\
\hline
\end{tabular}


conduzido por meio de uma autoridade qualquer, questionando e se contrapondo às razões postas como suficientes para serem admitidas como verdadeiras.

Por este motivo, a crítica não pode estar contida nos limites de um projeto filosófico, uma vez que se refere igualmente às formas de exercício de poder e às práticas sociais. Como virtude se insere como modo de exercer um "não querer ser assim governado, por isso, em nome desses princípios, em vista de tais objetivos e por meio de tais procedimentos, não dessa forma, não para isso, não por eles" (FOUCAULT, 1990, p.37). Então, a pergunta crucial que a contra conduta, como atitude crítica, formula é: como não ser governado de tal maneira? Não há nenhum fundamento de qualquer sentido nesta caracterização da atitude crítica em associação com o não querer ser governado: "Sejam estes de ordem natural, metafísica, ou divina, nem justificando as práticas de governar e nem para a atitude de não querer ser governado" (KRAEMER, 2011, p.293). É na imanência das artes de governar que se estabelecem tanto o ser governado quanto o governo de si. É uma atitude de recusa a se obedecer de qualquer forma. Câmara Leme destaca que "a atitude crítica em sua prática institui um novo éthos" (CÂMARA LEME, 2011, p. 111) que podemos denominar como sendo um éthos crítico, enquanto se expressa como ato poder em se recusar a ser conduzido de tal maneira e buscar outras formas de conduta ou para, de modo mais explícito, outros modos de se conduzir a si mesmo - efetivando assim uma "coragem" em se criar outros estilos de existência. Trata-se de como se observar a constituição do sujeito a partir de sua determinação política de ser governado de certa maneira. Nesta condição, o que podemos observar? Que ligada às artes de governar, detectamos uma arte de não ser governado, sempre se levando em conta que não se denota o sentido de “absolutamente não ser governado, mas como não ser governado desse modo, por tais princípios, em vista de tais objetivos e por meio de tais procedimentos" (FOUCAULT, 1990, pp.37-38). Quando Foucault se refere a esta atividade crítica, marcada pela expressão deste novo éthos, descreve uma recusa de obedecer de modo excessivo às práticas de governamento do pastorado cristão - que produzia uma forma de obediência por obediência, levando a um assujeitamento por individualização a partir da produção de uma verdade interior. Na condição do exercício do éthos crítico enquanto uma atitude virtuosa ao se questionar o modo de ser governado - isto é, a coragem de assumir mais intensamente sua própria conduta, opondo-se ao excessivo governamento - demonstra-se uma atitude de relação do sujeito consigo mesmo. Qual a implicação desta atitude? Implica no exercício de um éthos crítico, efetivando-se como uma arte de

\begin{tabular}{|l|l|l|l|l|}
\hline Qevista 2 Dialectus & Ano 4 & n. 11 & Agosto-Dezembro 2017 & p. 69-87
\end{tabular}


não querer ser governado de tal modo, apresentando um sentido mais negativo, enquanto determina a relação do indivíduo consigo mesmo, e, ao mesmo tempo, demonstra-se positivamente como uma atitude de governar mais a si mesmo. Este governar a si mesmo, como observa Kraemer, "seria ingênuo e inconsequente se não contasse com o trabalho prévio da atitude crítica (éthos crítico) com relação às formas específicas de governo que atuam na constituição do sujeito" (KRAEMER, 2011, p.294). Por fim, não se pode negligenciar que o governamento, enquanto exercício de poder, embasa-se nos discursos de verdade, logo o éthos crítico apresenta como objetivo principal a "verdade que sujeita, quer dizer, os efeitos de poder da verdade e os efeitos do poder" (CÂMARA LEME, 2011, p.113). Estabelece-se uma articulação entre poder/verdade/sujeito, levando-se em conta que o sujeito, ao exercer o éthos crítico, recusa-se a obedecer à verdade imposta por outros; e, assim, a se submeter a priori aos sistemas que nos fariam obedecer a um tipo de discurso de verdade que permita a intervenção do exercício abusivo de governamento - estabelecendo-se uma condição de vida mais autônoma, mais livre, ganhando assim a atitude crítica a condição de "a arte de inservidão voluntária, a da indocilidade refletida" (FOUCAULT, 1990, p.38).

Constatamos que a preocupação do como governar, no Ocidente, faz surgir simultaneamente o tema das artes de como se governar a conduta dos outros, enquanto o éthos crítico se constitui como a arte de não ser governado dessa forma, por que razão e por qualquer um. Segundo ainda a descrição de Foucault, este apresenta-se como "uma forma cultural geral, ao mesmo tempo como uma atitude moral e política" (FOUCAULT, 1990, p.38-40). Configura-se então, como um ato poder de contrapartida ao se ser governado de forma abusiva, visando escolher estilos próprios de conduzir sua vida - apresentando um problema ético de como assumir a coragem de exercer a tarefa equivalente ao governo de si; em como não ser conduzido por outros, mas ter a coragem de decidir se autogovernar.

\section{Éthos crítico e Autonomia}

O éthos crítico, enquanto atitude crítica, aposta na capacidade de abrir o espaço possível de liberdade, não se completando definitivamente, mas deixando sempre uma abertura para a possibilidade de mudanças, para a experiência possível de um auto desprendimento e de nos inventarmos sempre. No curso de 1983, denominado 
especificamente como Qu'est-ce que les Lumiéres? Foucault, ao se debruçar sobre o opúsculo “Que é o Esclarecimento?” (Was ist Aufklärung?), destaca como Kant aponta a coragem de se assumir o Sapere aude como a saída do homem de sua menoridade e atingir sua autonomia. Para sermos mais exatos: ousar pensar e agir por si mesmo, tornando-se autônomo de qualquer tipo de tutela, sendo capaz de se conduzir, sem necessitar de alguém que o conduza. Este é o mote da Aufklärung que Foucault destaca como uma máxima ou mesmo uma ordem. Como afirma o pensador:

A Wahlspruch é, de fato, uma máxima, um preceito, uma ordem dada a
outros ou a si mesmo, mas que é, ao mesmo tempo - e esta é a característica
que determina ao termo Wahlspruch ser um mote ou slogan - algo pelo que
nos identificamos e que nos possibilita nos distinguir dos outros
(FOUCAULT, 2008, p.28).

O que significa esta distinção? Aparentemente, que alguns podem seguir esta máxima e saírem da menoridade, enquanto outros, representando uma maioria, não apresentam possibilidades de fazê-lo. O que nos parece significativo é exatamente a noção de uma máxima no enunciado da Aufklärung. Um sinal indicativo que talvez seja um dever do homem, na condição de detentor da razão, ser capaz de orientar-se ou conduzir-se por conta própria. Mas quais seriam os motivos para a manutenção da menoridade.

Kant é bem incisivo quando nega que a "menoridade" seja determinada por algum fator natural. "O homem é o próprio culpado dessa menoridade se a causa dela não se encontra na ausência de entendimento, mas na falta de decisão e coragem de servir-se de si mesmo sem a direção de outrem" (KANT, 2008, p.61). Também precisa ficar claro que a menoridade não é determinada por algum grupo que detém o poder e o exerce sobre os outros; não é uma limitação jurídica de direitos ou a privação de seus direitos por atos de violência ou coação. Os fatores mais evidentes são de fato a ausência de coragem e decisão do homem em ousar sair de sua condição menor. Foucault assinala que Kant parece destacar a carência de uma vontade, uma falta ou um defeito que leva à incapacidade da Ausgang (saída) da menoridade. Poderíamos registrar então uma "ausência de coragem e decisão em assumir e exercer sua autonomia, saindo de seu estado de menoridade para atingir uma maioridade. Os homens possuem o meio para deixarem de ser menores, mas aparentemente ou são incapazes de fazê-lo ou não desejam conduzirem-se a si mesmos" (FOUCAULT, 2008, p.29). O autor ressalta o fato de que Kant se refere:

\begin{tabular}{|c|c|c|c|c|}
\hline Qovista Dialectus & Ano 4 & n. 11 & Agosto - Dezembro 2017 & p. $69-87$ \\
\hline
\end{tabular}




\begin{abstract}
A um ato, ou antes, a uma atitude, a um modo de comportamento, a uma forma de vontade que é geral, permanente e que não cria, em absoluto, um "direito", mas simplesmente uma espécie de estado de fato em que, por "complacência" e, de certo modo, por um obséquio levemente matizado de artimanha e de astúcia, pois bem, alguns assumiriam a direção dos outros (FOUCAULT, 2008, p.32).
\end{abstract}

Foucault começa a indicar que há uma espécie de "atitude" em se deixar conduzir por parte dos homens que seriam complacentes à direção dos outros; uma complacência em obedecer ao exercício de condução. Aqui, o estado de menoridade passa a ser caracterizado como uma obediência irrefletida. Haveria um vínculo entre um excesso de autoridade de um lado e a falta de coragem de atitude autônoma por outro, para os indivíduos orientarem-se por si mesmos, sem a anuência de outros. Observemos este trecho do texto sobre a questão da Aufklärung:

A preguiça e a covardia são aquele pelo que não damos a nós mesmos a
decisão, a força e a coragem de ter, conosco mesmos, a relação de autonomia
que nos permite nos servir da nossa razão e moral. E, por conseguinte, o que
a Aufklärung deverá fazer, o que ela está fazendo, pois bem, vai ser,
justamente, redistribuir as relações de governo de si e governo dos outros
(FOUCAULT, 2008, p.65).

Inicialmente, fica clara a leitura realizada por Foucault, ligando a questão da Aufklärung com a governamentalidade, enquanto a primeira é interpretada como uma tomada de atitude. Uma ação corajosa que visa escapar do excesso de governamento por parte da ação de outros. Não é uma condição de coerção que leva à permanência do estado de menoridade, mas dois fatores são apontados como a expressão da relação dos sujeitos com si mesmos: a preguiça (Faulheit) e a covardia (Feigheit) por parte da maioria dos homens são ressaltadas como os principais fatores para acomodarem os indivíduos em seus estados de menoridade. Assim, Kant em sua atualidade, identifica subjetividades carentes de "decisão" e "coragem", encontrando-se como que presos à "preguiça" e a "covardia", compondo o estado de "menoridade humana": a resignação sempre por culpa própria - dos indivíduos aos mais diferentes "tutores" (FOUCAULT, 2008, p.66). Deste modo, este filósofo critica a aceitação da condição humana em obedecer à direção de outros excessivamente, constituindo-se na escolha de se permanecer na condição de heteronomia, caracterizando-se, assim, como se se colocassem sob um contínuo estado de obediência integral. Esta excessiva condição de permanente obediência e de se deixar conduzir equivale à condição dos indivíduos em não se governarem a si mesmos e se deixarem governar de qualquer forma, sob qualquer condição, por qualquer um. Frédéric Gros ressalta que a Aufklärung ganha um 
aspecto importante, com referência à questão do governo, exatamente pela "atitude crítica levar o indivíduo menor a se contrapor a autoridade exterior e pensar por si mesmo" (GROS, 2006, p. 163).

Foucault faz referência aos exemplos que expressam a menoridade em como "Adotar um livro que faça às vezes de entendimento (Verstand), adotar um diretor que faça às vezes de consciência (Gewissen), adotar também um médico determinando a dieta a ser obedecida - eis o que ilustra, e, também, o que manifesta concretamente, o que é estar num estado de menoridade" (FOUCAULT, 2008, p. 29). Se expressa assim que a questão mais visceral se refere ao modo como o indivíduo permite a ação destas três autoridades na condução de sua forma de pensar e agir. Em outros termos: em como se deixar conduzir. Estabelece-se uma inação em se permitirem conduzirem, marcada pela condição de obedecer-se "aos pastores que conduzem o rebanho" - que poderíamos ilustrar na figura dos técnicos, especialistas e conselheiros, que, detentores do saber necessário e articuladores dos discursos de verdade sobre o saber que detêm, pensam e resolvem a melhor forma de sermos conduzidos. Afinal, se governa para melhorar a vida e a saúde dos indivíduos ou da população, assim como para aumentar sua riqueza e seu bem-estar. Segundo Gros: "Foucault formula a noção de menoridade, a partir da leitura de Kant da Aufklärung, como um modo de escapar do governo de si, para ser governado por outros" (GROS, 2006, p.166). Então, em que consiste, o modo de nos tornarmos mais autônomos, frente às táticas de governo? Como afirma Foucault:

Podemos dizer que o problema, ao mesmo tempo político, ético, social e filosófico, que se nos coloca atualmente não é o de tentar libertar o indivíduo do Estado e das suas instituições, mas o de nos libertarmos a nós do Estado, e do tipo de individualização que aí se retomar (FOUCAULT, 2001, p.197).

A partir desta condição, percebe-se como o pensador determina à filosofia - ou ao que pode denominar de uma atitude filosófica - o papel ético do éthos crítico como uma atitude-limite; isto é, refletir sobre os limites que nos constituem como sujeitos, não com o intuito de analisarmos nossa capacidade cognitiva, mas sim de agirmos de modo a não permanecermos formatados a estes limites que nos mantém naquilo que nós somos. Descreve-se esta atitude crítica como: "Éthos filosófico que seria possível caracterizar como crítica permanente que expressa não apenas o sentido de nosso ser histórico, mas também uma crítica permanente de nós mesmos" (FOUCAULT, 2001, p. 1397). Configura-se um éthos crítico que visa transformar a noção de crítica kantiana em uma atitude prática da razão para se alcançar modos de ultrapassagem dos nossos

\begin{tabular}{|l|l|l|l|l|}
\hline Qevista Dialectus & Ano 4 & n. 11 & Agosto-Dezembro 2017 & p. 69-87
\end{tabular}


limites. Objetiva-se transformar toda a crítica conduzida sob a forma de uma limitação necessária em uma "crítica prática que determina a forma de uma transgressão (ultrapassagem) ${ }^{5}$ possível” (FOUCAULT, 2001, p.1393). O éthos crítico trabalha sobre os nossos limites, na análise histórica das formas das subjetividades atuais, e como os laços entre poder e verdade são essenciais para as práticas de assujeitamento. Recusa-se assim qualquer tipo de fundamento que interprete o sujeito, em sua constituição, a partir de uma essência fixa, acabada e idêntica a si mesmo. Como observa Dekens: "Foucault não se dispõe a analisar as estruturas universais do conhecimento, mas as condições históricas de emergência de um pensamento ou de uma ação, que nos identifica em como nos constituímos como sujeitos que somos" (2011, p.36). Tal enquete, longe de ser transcendental no sentido de se elaborar as condições de uma nova metafísica, encontra-se no campo da atitude crítica, enquanto a expressão de uma "ética da verdade" como uma atitude por parte do indivíduo em assumir a coragem da verdade de si, para poder exercer maior autonomia sobre sua conduta, recusando-se assim a ser permanentemente governado por outros - uma coragem ética e também política por parte do sujeito que assume o exercício do éthos crítico, pela qual se decide pensar e agir por si mesmo, conduzindo sua própria existência de modo reflexivo, para ultrapassagem dos limites impostos que nos assujeitam. As contra condutas expressas como movimentos de contestação religiosa ao governo pastoral, os levantes contra o abuso dos poderes monárquicos e a ousadia de se assumir outras verdades, contestando as professadas e praticadas, segundo Braga Júnior, "fixam o exercício da atitude crítica (éthos crítico) em termos de poder, que denotam relutância a incorporá-lo em modos de obediência excessiva" (BRAGA JR., 2007, p. 171). Fomenta-se um ganho maior de autonomia, semelhante a como invoca Kant em seu texto de 1784. Porém, há uma modificação fundamental, segundo a perspectiva de Foucault, no modo em como se dá a relação entre sujeito e verdade: esta não se limita ao campo do conhecimento ou na iniciativa de se analisar os critérios do que se pode conhecer, mas sim em termos de obrigação e coragem de governar mais a si mesmo de modo livre e crítico. Como salienta Gros, "a ligação com a verdade, esta é menos de natureza epistêmica, do que propriamente ética" (GROS, 2006, p.166).

\footnotetext{
${ }^{5} \mathrm{O}$ termo "ultrapassagem" designa de forma mais adequada esta questão de a atitude-limite como ato poder de prática da liberdade, desassujeitando-se, e, principalmente, fazendo-o de forma refletida e mais exitosa possível, ciente da necessidade de experimentar sua atualidade. A transgressão denota um caráter mais psicológico de pura rejeição ou reação à condição do sujeito e sua atualidade.
}

\begin{tabular}{|l|l|l|l|l|}
\hline Q Rovista Dialectus & Ano 4 & n. 11 & Agosto - Dezembro 2017 & p. 69-87 \\
\hline
\end{tabular}


Contudo, Foucault, a partir da invocação de uma atitude audaz em se pensar e agir por si mesmo (inspirando-se no sapere aude) diverge das condições da autonomia Kantiana que a coloca no âmbito de sujeitos razoáveis e que determinam a si próprios, as suas próprias leis para agir. Sendo assim, a razão é autônoma quando se encontra livre de influências heterônomas, livre das inclinações humanas. Por seu lado, o autor refere-se a sujeitos que exercitam sua autonomia e que se constituem de modo mais livre, não pelo motivo de se colocarem na condição de sujeitos de si mesmos, como se fossem cernes da racionalidade, mas que, assumindo a coragem do éthos crítico enquanto atitude-limite, se aposta na possibilidade de ultrapassar os seus próprios limites. Obviamente, esta prática de liberdade é refletida, mas, aqui, não se legitima "a razão como luz despótica, mas a razão que só tem efeito de libertação, desde que ela consiga libertar-se de si mesma” (FOUCAULT, 2001, p. 1586-1587). O vocabulário referente à relação entre autonomia e heteronomia é rompido por Foucault, compreendendo que não se trata de fato de uma emancipação total do sujeito, mas sim como uma atitude de criação de si mais autônoma e livre (RABINOW, 1984, p. 42-43). Desta feita, Kraemer observa que autonomia e liberdade, em Foucault, são parciais e locais (KRAEMER, 2011, p.309) apresentando-se como práticas de liberdade sempre dinâmicas e instáveis, pelo menos por algum tempo, sempre ocorrendo em determinadas circunstâncias e condições muito específicas. Desta forma, não se estabelece o sentido de uma emancipação total do sujeito devido a ser possuidor e assumir a autonomia por ser possuidor de uma "natureza racional", fator que pode ser detectado no sentido de expressão de autonomia kantiano; uma autonomia da vontade legisladora que expressaria a capacidade da razão se autodeterminar, livre de qualquer tipo de impedimentos empíricos e por este motivo, capaz de uma emancipação total da humanidade de sua condição menor.

Foucault recusa a noção de um sujeito constituinte que, de acordo com a noção de autonomia kantiana, se constituiria como a essência e a condição de uma vontade livre de qualquer contingência histórica, concebendo um sujeito liberto das práticas que constituem os mecanismos das relações de poder, fato que segundo a perspectiva foucaultiana é implausível. No que concerne à formulação das noções de atitude crítica como virtude (1978) e a de éthos filosófico (1983), ambas reforçam a radicalidade do éthos crítico - que está diretamente imbricada com o estilo de vida que cada indivíduo busca estabelecer para governar mais a si, no qual se vejam implicadas as relações que este mantém com si mesmo e com outros. Reflete-se a importância de cada indivíduo

\begin{tabular}{|l|l|l|l|l|}
\hline Qevista 2 Dialectus & Ano 4 & n. 11 & Agosto-Dezembro 2017 & p. 69-87
\end{tabular}


assumir, de modo radical, o seu estilo de ser, como possibilidade de se governar mais intensamente. Então, partindo desta perspectiva, problematizam-se as condições para que o indivíduo cuide de seu próprio estilo de éthos na sua atualidade, situando-se no domínio de uma ética que não se limita ao simples cumprimento moral de valores e normas, mas sim a uma reflexão e ação contínua do indivíduo sobre si mesmo, em convivência direta com os outros.

Note-se a presença da noção de "estilização" que retira a subjetivação ética da questão referente à construção ou adesão a um modelo de conduta que legisla uma condição de conformidade - propiciando o assujeitamento dos indivíduos a um modo de existência de acordo com um padrão comum determinado para todos. Tal conjuntura exige a saída desta menoridade - que se constitui como nossa submissão aos mecanismos persistentes e sutis de governamentalidade, não devido a uma coerção externa, mas exatamente ao fato dos homens acomodarem-se a serem conduzidos intensamente. A menoridade se estabelece exatamente pela inexistência de uma vontade de não nos deixarmos governar de modo abusivo. Deve-se assumir a coragem ética pela qual se decide pensar por si mesmo, esta coragem relevante da atitude crítica se coloca como superior à simples lucidez permitida pelo estudo transcendental. Bernauer e Mahon afirmam que nesta atitude, Foucault aponta "uma prática de liberdade para transgredir (ultrapassar) os mecanismos de poder-saber-subjetividade que constituem o governamento, diferente do que se relaciona comumente com o Estado de direito e as estruturas burocráticas" (BERNAUER et al, 1996, p.154). Foucault retira para sua análise entre governamento abusivo e éthos crítico, dois pontos importantes da Aufklärung: uma prática de autonomia pessoal e o exercício da razão crítica. Pode-se observar que diferentemente da visão da Aufklärung kantiana, defensora e estimuladora de uma liberdade abstrata e universal, destaca-se a percepção de um éthos de liberdade na análise filosófica foucaultiana, caracterizando-se este éthos de liberdade não como eterno e universal ou apresentando como fundamento um sujeito essencialmente determinado como livre. Pode-se apontar o éthos crítico, enquanto identificado com este éthos de liberdade, como uma prática de liberdade ou uma liberdade prática concreta. Sempre por se refazer e imbricada diretamente com uma agonística como o poder.

\section{Éthos crítico enquanto prática de liberdade}

\begin{tabular}{|l|l|l|l|l|}
\hline Q Ronista Dialectus & Ano 4 & n. 11 & Agosto - Dezembro 2017 & p. 69-87 \\
\hline
\end{tabular}


Problematiza-se um éthos que expressa uma prática de liberdade que possa abrir possibilidades para novas relações do indivíduo consigo mesmo e com outros. Prática de liberdade que precisa ser compreendida como: "a possibilidade de não mais ser, fazer ou pensar o que somos, fazemos ou pensamos" (FOUCAULT, 2001, p.1392) Prática de liberdade que requer um trabalho de transformação sobre nós mesmos, sobre os nossos limites. Desenha-se uma subjetivação ética e a sua prática se apresenta como uma atitude de liberdade, sendo caracterizada por "um agonismo, uma permanente provocação presente nas relações de poder nas quais estamos inseridos" (FOUCAULT, 2001, p. 1057). A leitura da crítica e sua relação com a Aufklärung, aponta para um ponto de reflexão que permite a problematização de uma autoconstituição de si como sujeito ético. Esta subjetivação efetiva-se na tensão entre ética e política, entre o governo dos outros e o governo de si.

De fato, alude-se a um trabalho sobre si que, Foucault reconhece, foi colocado por Kant com relação ao problema do sujeito de conhecimento e ético. Como afirma o autor, a solução foi: "encontrar um sujeito universal que, como tal, poderia ser sujeito de conhecimento, mas que requereria, sem dúvida, uma atitude ética - precisamente, é esta relação com o si que Kant propõe na Crítica da razão prática” (KAMINSKY, 2003, p.84). Todavia, o que Foucault aponta como o cerne mais importante nesta problemática kantiana formulada em torno de um sujeito autônomo, ético e universal, se localiza exatamente nas questões que são subjacentes a esta proposta de uma racionalidade ética procedimental universal:

\footnotetext{
Kant afirma: devo reconhecer-me como sujeito universal, isto é, devo constituir-me em cada uma de minhas ações como sujeito universal, em conformidade com regras universais. As antigas interrogações eram reinterpretadas; como posso me constituir a mim mesmo como sujeito ético? Como me reconhecer como tal? São necessários os exercícios ascéticos? Ou simplesmente esta relação kantiana com o universal me faz ético ao estar em conformidade com a razão prática? Deste modo, Kant introduz um novo enfoque em nossa tradição, pelo qual o si não é meramente dado, mas sim que se constitui na relação de si mesmo como sujeito (KAMINSKY, 2003, p.85).
}

Foucault alija a figura do sujeito transcendental kantiano, reconhece um modo de subjetivação ética de si, presente na questão kantiana do sujeito universal e ético, resultante exatamente de um enfrentamento sobre si mesmo enquanto um trabalho de transformação sobre si. Atentemos para o significado que o éthos crítico apresenta, enquanto uma prática de subjetivação ética, caracterizando-se como uma forma de

\begin{tabular}{|l|l|l|l|l|}
\hline Q Rovista Dialectus & Ano 4 & n. 11 & Agosto - Dezembro 2017 & p. 69-87 \\
\hline
\end{tabular}


inconformidade em como se é conduzido e em como o indivíduo conduz a si mesmo diante dos outros. Esta subjetivação ética denota a implicação e ligação direta entre subjetividade, verdade e liberdade.

\section{Conclusão}

Deve-se explicitar que, analisando e problematizando, de forma articulada, verdade, poder e subjetividade no âmbito do que vai designar como "governamento pela verdade", Foucault realiza o deslocamento de sua reflexão para o eixo do éthos. Ele descreve uma atitude crítica, ou, em outro sentido, um éthos crítico, como condição dos indivíduos ao se recusarem a serem governados de tal maneira, identificando-se assim como uma contra conduta que pode ser qualificada como uma prática de liberdade ética, contrapondo-se a um governo alheio e excessivo, a partir de uma inquietude que leva à questão de como não ser governado de modo absoluto. Inteiramente relacionada à capacidade de fazer-se obedecer.

Ao obedecer, o indivíduo se permite ser dirigido, isto é, sua conduta está ligada a uma relação de assujeitamento de consciência. Este indivíduo é conduzido em seu modo de pensar e agir - apresenta-se na condição de ser governado, aceitando sê-lo por alguma autoridade a que estaria ligado por um vínculo de total obediência. Aqui, verifica-se a grande questão inserida na governamentalidade ocidental, qual seja: a condição de se governar os outros será eficaz se a racionalidade daqueles sobre os quais o governamento é exercido estiver orientada, determinada, direcionada, organizada. Só será possível o exercício de governo sobre o outro se o governado estiver de algum modo ajustado ou disposto para a produção da obediência. Deste modo, a produção de racionalidades suficientemente obedientes aos objetivos do poder, em seu exercício abusivo, transparece como um problema político historicamente importante. O governado não pode ser resultado espontâneo de processos que escapam ao exercício do poder; ao contrário, é preciso que sua sujeição (assujeitamento) seja suficientemente suscitada, provocada e motivada pela e para a obediência. Sendo assim, as artes de governar, como no caso exemplificado do pastorado, apresentam todo o desenrolar da questão de como governar e a quem governar, sendo necessário que o conduzido, de algum modo, obedeça. Contudo, não temos um sujeito vitimado pelas práticas do poder, como se não fosse possível, por meio de escolhas éticas e políticas, que se afirmassem 
enquanto práticas de resistência. Destaca-se uma questão que exprime uma extrema conotação ética e também política: nas análises sobre as práticas concretas das relações de poder e sua articulação com a verdade, marcadas por estratégias e técnicas que visam constituir subjetividades assujeitadas e normalizadas, há também práticas de resistência que visam à criação de espaços de liberdade? Se assim for, a atividade filosófica foucaultiana é política porque trataria de articular a preocupação ética com as lutas políticas, interpelando a reflexão crítica contra as técnicas abusivas de governo pela enunciação da verdade. A partir desta condição, podemos destacar um problema político bem atual: a agonística entre poder e liberdade, que marca a condição de existência da liberdade como oposição a um poder, ou melhor, a poderes, que não impedem a liberdade, mas a excitam e a limitam. Castelo Branco chama nossa atenção exatamente para o caráter agonístico da filosofia, ligada diretamente em seu discurso engajado, pelo menos na percepção de Foucault, às práticas de liberdade (CASTELO BRANCO, 2011, p.158). Por este motivo, o pensador retira da sua análise de poder, todo o caráter negativo e repressor referente a uma interpretação filosófica e política que vai recusar e critica.

\section{REFERÊNCIAS:}

BERNAUER, J. W. \& MAHON, M. The ethics of Michel Foucault. In: The Cambridge Companion to Foucault. New York: Cambridge Press, 1996.

BRAGA JR, M. Michel Foucault - a legitimidade e os corpos políticos. São Paulo: Ed. Manole, 2007.

CÂMARA LEME, J. L. Foucault, Kant e a crítica política. In. Kant e-prints, Série 2, v. 6, n. 2, p. 113, Jul. Dez., 2011.

CASTELO BRANCO, G. \& VEIGA-NETO, A. Foucault: filosofia \& política. Belo Horizonte: Autêntica Editora, 2011.

DEKENS, O. Michel Foucault. La vérité de mes livres est dans l'avenir. Paris: Armand Colin, 2008.

DELEUZE. G. Conversações. Trad. Peter Pál Pelbart. São Paulo: Ed. 34, 1992.

ESCOBAR, C. H. Michel Foucault - O Dossier: últimas entrevistas. Rio de Janeiro: Editora Taurus, 1984.

FOUCAULT, M. Qu`est-ce que la Critíque? Critique et Aufklarung. Bulletin de la Société française de philosophie, vol 82, n. 2, avr/juin, 1990.

Dits et Écrits II, 1976-1988. 2. Ed. Paris; Gallimard, 2001.

\begin{tabular}{|c|c|c|c|c|}
\hline Q Rovista Dialectus & Ano 4 & n. 11 & Agosto - Dezembro 2017 & p. $69-87$ \\
\hline
\end{tabular}


. Segurança, Território e População: curso dado no Collège de France (19771978). Tradução de Eduardo Brandão; revisão de Claudia Berliner. - São Paulo: Martins Fontes, 2009.

Le Gouvernement de Soi et des Autres. Cours au Collége de France (19821983), Paris: Gallimard/Seuil, 2008.

GROS, F. Foucault et le Lumiéres. Bordeux : CIBEL, 2006.

KAMINSKY, G. El yo minimalista y otras conversaciones con Michel Foucault. Tradução de Graciela Staps. Buenos Aires: La Marca editor, 2003.

KANT, I. Resposta à pergunta: O que é Esclarecimento? In. Textos Seletos. Introdução de Emmanuel Carneiro Leão. Tradução Raimundo Vier e Floriano de Sousa Fernandes. Petrópolis: Ed. Vozes, 2008.

KRAEMER, C. Ética e Liberdade em Michel Foucault. Uma leitura de Kant. São Paulo: EDUSC, 2011.

OKSALA, J. Como ler Foucault. Tradução de Maria Luiza X. de A. Borges; revisão técnica de Alfredo Veiga-Neto - Rio de Janeiro: Zahar, 2011.

RABINOW, P. The Foucault Reader. Translate. Catherine Potter. New York: Pantheon, 1984.

VEYNE, P. Foucault revoluciona a história. In: Como se escreve a história: Foucault revoluciona a história. Brasília, Ed. Univ. de Brasília, 1982. 